\title{
Pancreatic Incidentaloma: Case Report, Diagnosis and Management
}

Samir Lafrouji", Faysal Alazaoui, Hadj Omar El Malki, Mountassir Chefchaouni, Lahsen Ifrine, Abdelkader Belkouchi Chirurgie A

Ibn Sina Hospital, Mohammed V University of Rabat, Morocco

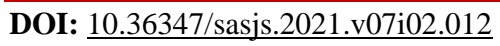

| Received: 02.02.2021 | Accepted: 12.02.2021 | Published: 16.02.2021

*Corresponding author: Samir Lafrouji

Abstract

A pancreatic incidentaloma is a cystic or solid lesion of the pancreas that is accidentally diagnosed during a routine $\mathrm{x}$ ray exam to explore another organ unrelated to pancreatic disease. Nowadays, thanks to the increased performance of radiological explorations, the fortuitous discovery of pancreatic incidentalomas has become more and more frequent. This discovery is a delicate problem in front of which a complete assessment will be systematically carried out including abdominal CT, pancreatic MRI and echendoscopy in order to precisely determine the nature of this incidentaloma. The choice of the best therapeutic option remains difficult and will be between excisional surgery which can be risky with fairly significant morbidity or monitoring which can be problematic in case of a diagnostic error.

Keywords: Incidentaloma, Diagnosis, Management, Pancreatic Disease.

Copyright () 2021 The Author(s): This is an open-access article distributed under the terms of the Creative Commons Attribution 4.0 International License (CC BY-NC 4.0) which permits unrestricted use, distribution, and reproduction in any medium for non-commercial use provided the original author and source are credited.

\section{INTRODUCTION}

A pancreatic incidentaloma is a cystic or solid lesion of the pancreas that is accidentally diagnosed during an X-ray exam to explore another organ, unrelated to pancreatic disease. Thanks to the improved performance of radiological explorations nowadays, the fortuitous discovery of pancreatic lesions has become more and more frequent, but despite all these technological advances, it remains difficult to determine whether it is a malignant tumor (adenocarcinoma , cystadenocarcinoma, mucinous intraductal papillary tumor (TIPMP), pancreatic metastasis, etc.) or benign with malignant potential (mucinous cystadenoma, benign TIPMP, endocrine tumor, etc.), or a benign tumor (serous cystadenoma) [ 1-4].

However, you must specify the nature of these lesions to choose between surgery that can expose to morbidity or mortality risk or the surveillance that is binding for the patient because he must accept the existence of an eventual misdiagnosis.

The choice between these two attitudes is difficult and will be governed by many factors: the age and the operability of the patient, the size and the appearance of the lesion, the location in the pancreas, the psychological state of the patient and his ability to accept rigorous surveillance or unsafe surgery.
It remains difficult to establish a regimen simply, that is why in front of each case it will be necessary to make a full initial assessment to minimize the margin of error.

\section{CASE REPORT}

This is a 70 years old patient, followed for 02 years in urology for benign prostatic hypertrophy.

Following a routine urology consultation for recurrent voiding burns, an abdomino-pelvic CT scan led to the fortuitous discovery of a tumor process in the body of the pancreas. An Assessment of extension and resecability (CT TAP + MRI pancreatic) was done, it is a lesional process cystic located at the pancreatic body, measuring $03 \mathrm{~cm}$ long, resecable and classified T2NOMO.

The case was discussed in oncology RCP, taking into account the age of the patient, his inability to ensure rigorous monitoring, the size and site of the lesion in the pancreas, the best therapeutic option was surgery. The patient was operated; the procedure performed is a caudal pancreatectomy with splenic preservation under laparoscopy. No post-operative consequences were found, no pancreatic fistula was detected. 


\section{DISSCUSSION}

\section{What are the pancreatic lesions that can be seen in an asymptomatic patient?}

When a cystic lesion

is accidentally discovered in an asymptomatic patient, it is logical to assume that it is a cystic tumor or a true cyst. All the hypotheses are then possible from a lesion without degenerative potential to a lesion with degenerative potential.

According to the series by Ikeda et al. [5], the ultrasound abdominal can identify a fortuitous pancreatic tumor potentially malignant with a rate of $1 / 5000$ in asymptomatic subjects.

According to the study of Leborgne et al. [6], $32 \%$ of patients with serous cystadenoma and $26 \%$ of those with mucinous cystadenoma were asymptomatic. Pseudo-papillary and solid tumors are discovered incidentally in $10 \%$ to $40 \%$ of cases [7-9]. Are more often symptomatic than other cystic tumors [1]. In a series of TIPMP published by [10], $20 \%$ of TIPMP were asymptomatic and were Benign. The cystadenocarcinoma is rarely discovered incidentally [11].

The increase in sensitivity of detection of tumors pancreatic by imaging techniques (MRI and echoendoscopy) has increased the incidence rate of pancreatic lesions discovered incidentally and the diagnosis rate erroneous of pseudocyst in patients with a cystic tumor fell by $50 \%$ [1].

The gender, age and location of the incidentaloma in the pancreas can they predict the diagnosis?

The predominance of the female sex in both cystadenomas and TPPS does not allow a conclusion to be drawn in favor of one cystic tumor over another. While TPPS are more readily observed in young women, cystadenomas are also encountered at the same age and therefore cannot be excluded on this single epidemiological data.

In children and adolescents, cystic tumors are rare. Congenital Cysts, CS, the TPPS and pancreatoblastoma are most frequent in the AFC series [12].

Classically, CMs are more frequently found in the body and tail of the pancreas, while TIPMP or CS is more of a cephalic location. Location is not, however, decisive in guiding the diagnosis.

The pancreatic incidentaloma cystic: have they a frequently degenerative potential?

According to the series of Ikeda based on patients of injury cystic asymptomatic of discoveries fortuitous, 22 patients showed a cystic tumor malignancy of 271 [5]. According to the series by Fernandez del Castillo [13], 17\% of asymptomatic patients presented with an in-situ or invasive cancer during surgery and $42 \%$ with a precancerous lesion. Among the 1 cystic asymptomatic lesions, the proportion of degenerate cystic tumor increased from 3.5 to $26 \%$ when the size of the lesion exceeded $2 \mathrm{~cm}$.

The existence of dilatation of the pancreatic duct in case of an incidentaloma: evokes her a diagnosis?

In an asymptomatic patient, it is the diagnosis of TIPMP that must be retained as a priority. The rare differential diagnoses are the chronic pancreatitis and extrinsic compression of the principal pancreatic duct by a cystic tumor with an upstream expansion of the duct.

\section{What are the morphological exams for the differential diagnosis of a cystic tumor of the pancreas?}

The ultrasound and CT abdominal are the most often radiological examinations that are the reason of the discovery of asymptomatic lesions of the pancreas. Once the diagnosis of 1 intrapancreatic tumor confirmed, the morphological examinations should specify the nature of this lesion (Table 1).

The performance of abdominal ultrasound in the event of a microcystic component is 78 to $86 \%$ [14, 16]. CT scan confirms the microcystic appearance in $69 \%$ of cases [16].

The echoendoscopy remains the examination of choice for the diagnosis of CS viewing microcysts that are more evocative when central.

The radiological criteria allowing evoking a $\mathrm{CM}$ are: the presence of macrocystic lesions, the thickening of the walls, the vegetation and echogenic content [17]. The presence of tissue damage is suggestive of cystadenocarcinoma. The performance of the echoendoscopy exceed by far those of ultrasound and CT scan to differentiate the cystadenoma from the cystadenocarcinoma [14].

For TPPS, MRI is currently the reference examination for diagnosis; it allows observing a lesion with a mixed component, solid and liquid (areas of necrosis or hemorrhage). Given the often large size of these lesions, Echoendoscopy may be limited.

Congenital Cysts are hypodense lesions on CT and strictly anechoic. Their wall is thin and does not rise during the injection of contrast product.

For all these lesions, retrograde pancreatography is off interest because they exceptionally communicate with the main pancreatic duct. 


\section{Which asymptomatic cystic lesions do we offer a surgery?}

The majority of these tumors are benign but with uncertain evolutionary potential, making the taking in charge often difficult: simple monitoring vs surgery.

The differential diagnosis between pseudotumor infiltration of the pancreas and a solid tumor is often difficult. In this situation we must use the clinical and biological context (absence of deterioration of the general conditions of the patient and the level of tumor markers) and imaging. Pancreatic biopsy could be helpful in showing a rich infiltrate in $\mathrm{T}$ cells or eosinophils and the absence of tumor cells.

The cystic lesion size lower $2 \mathrm{~cm}$ is more often found incidentally whose nature remains quite difficult to specify. For example, in the presence of a lesion cystic the pancreas unilocular measuring $10 \mathrm{~mm}$ in diameter, the distinction between a cystadenoma, serous Microcystic, a true cyst and mucinous cystadenoma which responds not to the criteria radiological defined by Johnson et al [14] is impossible.

Surgical resection must be considered only in cases of malignant tumor, potentially malignant or questionable (if CM, STPP, and NET). The decision is more difficult in the event of a small lesion $(<2 \mathrm{~cm})$, whether it is a probable mucinous cystadenoma, an endocrine tumor or an isolated dilation of a small secondary duct corresponding to an early TIPMP, because the risk of malignant transformation of these lesions is undoubtedly quite low.

It is therefore essential to take the terrain into account (age of the patient, general state). The supposed benefit of the surgical resection of the lesion and the risks of surgery, even limited, must be balanced.

A tumor that is a priori malignant must be removed by a regulated intervention (cephalic duodenopancreatectomy, left pancreatectomy with or without splenectomy). A pancreatectomy plant can be envisaged in the case of benign isthmic lesion [18].

An enucleation can be discussed for a look tumor benign located sufficiently remote $(>2-3 \mathrm{~mm})$ of the pancreatic duct and if the relationship with the peripancreatic vessels and duodenal permit.

\section{Monitoring and therapeutic abstention: when and how?}

The monitoring with therapy abstention is indicated for patients with serous cystadenoma well documented and asymptomatic or if the general state dont allow surgery resection.

In the event of a limited TIPMP to the secondary ducts in elderly and asymptomatic subjects, the tendency is to offer simple monitoring by annual abdominal ultrasounds. More expensive or invasive explorations should be discussed when a change in the lesion is suspected or when it becomes symptomatic.

\section{Pancreatectomy for pancreatic incidentalomas: What are the risks?}

According to M.Bouquot's study [19] on 881 pancreatectomies: $32 \%$ of patients were asymptomatic and had an incidentaloma, the median size of incidentalomas was $30 \mathrm{~mm}$, and $49 \%$ of INC was cystic in nature. $61 \%$ of INC were located on the left, $49 \%$ of INC were benign. Severe morbidity was lower for INC (15\% vs. $37 \%)$. An Age > 55 years, tumor size> 20 $\mathrm{mm}$, and biliary dilatation were the independent risk factors of malignancy of the INC, the likelihood of malignancy was $90 \%$ when the three factors were combined.

Conclusion of the study: INC represents $30 \%$ of pancreatectomies and is malignant in $50 \%$ of the cases. A separate European retrospective study, covering 127 pancreatic laparoscopic resections (enucleation $[\mathrm{n}=24]$, left pancreatectomy with $[\mathrm{n}=37]$ and without $[\mathrm{n}=61]$ splenectomy, cephalic pancreatectomy $(n=3)$ reported an overall rate of complications that was around $39 \%$, with a fistula rate of $24 \%$ post-enucleation and $18 \%$ post left pancreatectomy. the mortality after surgery was zero. pancreatic fistulas constitute the main complication with an average rate of $20 \%$. [20-22].

\section{REFERENCES}

1. Le Borgne J, de Calan L, Partensky C. Cystic tumors of the pancreas. $1^{\text {st }}$ ed. Paris: Arnette; 1997.

2. Kimura W, Sasahira N, Yoshikawa T, Muto T, Makuuchi M. Duct- ectatic type of mucin producing-tumor of the pancreas. New concept of pancreatic neoplasia. Hepatogastroenterology. 1 996; 43: 692-70.

3. Terris B, Ponsot P, Paye F, Hammel P, Sauvanet A, Molas G. Intraductal papillary mucinous tumors of the pancreas confined to secondary ducts show less aggressive pathologic features as compared with those involving the main pancreatic duct. Am J Surg Pathol. 2000; 24: 1372-7.

4. Klöppel G, Solcia E, Longnecker DS, Capella C, Sobin LE. Histological typing of tumours of the exocrine pancreas. Springer Science \& Business Media; 1996.

5. Ikeda M, Sato T, Morozumi A, Fujino MA, Yoda Y, Ochiai M, Kobayashi K. Morphologic changes in the pancreas detected by screening ultrasonography in a mass survey, with special reference to main duct dilatation, cyst formation, and calcification. Pancreas. 1994 Jul 1;9(4):508-12.

6. Le Borgne J, de Calan L, Partensky C, French Surgical Association. Cystadenomas and cystadenocarcinomas of the pancreas: a 
multiinstitutional retrospective study of 398 cases. Annals of surgery. 1999 Aug;230(2):152.

7. Buetow PC, Buck JL, Pantongrag-Brown L, Beck KG, Ros PR, Adair CF. Solid and papillary epithelial neoplasm of the pancreas: imagingpathologic correlation on 56 cases. Radiology. 1996 Jun;199(3):707-11.

8. Miloudi N, Sabbagh S, Attaoui MA, Abid SB, Gharbi L, Khalfallah MT. Tumeur pseudopapillaire et solide du pancréas. JCC Open. 2013 Jan 1;1(1):44-8.

9. Sheehan M, Latona C, Aranha G, Pickleman J. The increasing problem of unusual pancreatic tumors. Archives of Surgery. 2000 Jun 1;135(6):644-50.

10. Barbe L, Ponsot P, Vilgrain V, Terris B, Fléjou JF, Sauvanet A. Pancreatic mucinous papillary intraductal tumors. Clinical and morphological aspects in 30 patients. Gastroenterol Clin Biol. 1997; 21: 278-86.

11. Warshaw AL, Compton CC, Lewandrowski K, Cardenosa G, Mueller PR. Cystic tumors of the pancreas. New clinical, radiologic, and pathologic observation in 67 patients. Ann Surg. 1990; 212: $432-43$.

12. Heloury Y. Cystic tumors of the pancreas in children: a diagnostic and therapeutic strategy. In: J Le Borgne, L de Calan, C Partensky. Cystic tumors of the pancreas. Paris, Arnette, 1997: 151156.

13. Fernández-del Castillo C, Targarona J, Thayer SP, Rattner DW, Brugge WR, Warshaw AL. Incidental pancreatic cysts: clinicopathologic characteristics and comparison with symptomatic patients. Archives of Surgery. 2003 Apr 1;138(4):427-34.

14. Johnson CD, Stephens DH, Charboneau JW, Carpenter HA, Welch TJ. Cystic pancreatic tumors: CT and sonographic assessment. American Journal of Roentgenology. 1988 Dec 1;151(6):1133-8.
15. Levy M, Levy P, Hammel P, Zins M, Vilgrain V, Amouyal G, Amouyal P, Molas G, Flejou JF, Voitot H. Diagnosis of cystadenomas and cystadenocarcinomas of the pancreas. Study of 35 cases. Gastroentérologie clinique et biologique. 1995 Feb 1;19(2):189-96.

16. Procacci C, Graziani R, Bicego E, BergamoAndreis IA, Guarise A, Valdo M, Bogina G, Solarino U, Pistolesi GF. Serous cystadenoma of the pancreas: report of 30 cases with emphasis on the imaging findings. Journal of computer assisted tomography. 1997 May 1;21(3):373-82.

17. Koito $K$, Namieno $T$, Nagakawa $T$, Shyonai $T$, Hirokawa N, Morita K. Solitary cystic tumor of the pancreas: EUS-pathologic correlation. Gastrointestinal endoscopy. 1997 Mar 1;45(3):26876.

18. Rotman N, Sastre B, Fagniez PL. Medial pancreatectomy for tumors of the neck of the pancreas. Surgery. 1993; 113: 532-5.

19. Pancreatectomy for pancreatic incidentaloma: what are the risks? Bouquot M, Gaujoux S, Cauchy F, DJ Birnbaum, Dokmak S, Aussilhou B, Lévy P, Sauvanet A. Department of Hepatic and Pancreatic Surgery, Clichy, France Department of Gastroenterology, Clichy, France

20. Lillemoe KD, Kaushal S, Cameron JL. Distal pancreatectomy: indications and outcomes in 235 patients. Ann Surg. 1999; 229: 693700.

21. Benoist S, Dugue L, Sauvanet A. Is there a role of preservation of the spleen in distal pancreatectomy? J Am Coll Surg. 1999; 188: 255260.

22. Broughan TA, Leslie JD, Soto JM, Hermann RE. Pancreatic islet cell tumors. Surgery. 1986; 99: 671678 . 